\title{
Calculated Radioactivity Yields of Cu-64 from Proton-Bombarded Ni-64 Targets Using SRIM Codes
}

\author{
I. Kambali* \\ Center for Radioisotopes and Radiopharmaceuticals Technology, National Nuclear Energy Agency \\ Puspiptek Area Serpong, Tangerang 15310, Indonesia
}

\section{ARTICLE INFO}

Article history:

Received 23 October 2014

Received in revised form 24 December 2014

Accepted 27 December 2014

Keywords:

Stopping power range

Proton beam

Ni target

${ }^{64} \mathrm{Cu}$ production

\begin{abstract}
A B S T R A C T
The End-Of-Bombardment (EOB) Yields from ${ }^{64} \mathrm{Ni}(\mathrm{p}, \mathrm{n}){ }^{64} \mathrm{Cu}$ nuclear reaction have been calculated for optimizing irradiation parameters that correspond to future ${ }^{64} \mathrm{Cu}$ radionuclide production using the BATAN's 26.5-MeV cyclotron in Serpong. Enriched Ni target thickness, proton beam current and irradiation time which play significant role in the success of the Positron Emission Tomography (PET) radionuclide were also discussed in this paper. For a $26.5-\mathrm{MeV}$ proton beam, the optimum target thickness for ${ }^{64} \mathrm{Cu}$ production was nearly $1.5 \mathrm{~mm}$ with yields up to $560 \mathrm{mCi} / \mu \mathrm{A} . \mathrm{hr}$ at the end of the irradiation. The comparisons with some selected experimental data indicated that the much-lower-than-expected EOB yields were mainly due to incorrect target thickness prepared for the irradiation. Nevertheless, these calculations were in good agreement with the previous predicted data with a maximum difference of less than $10 \%$. The discrepancies were mostly due to different cross-section data employed in the calculations.
\end{abstract}

\section{INTRODUCTION}

Radionuclide ${ }^{64} \mathrm{Cu}$ produced via nuclear reaction ${ }^{64} \mathrm{Ni}(\mathrm{p}, \mathrm{n}){ }^{64} \mathrm{Cu}$ has been of great interest due to its potential applications in medical field, particularly for cancer diagnosis. Successful production of the Positron Emission Tomography (PET) radionuclide requires thorough understanding of the irradiation parameters, including energy of proton as an incident particle, target preparation and thickness, proton beam current as well as irradiation time. Knowledge about optimum proton energy is essential since it corresponds to the threshold energy and cross-section/excitation function of a particular target when the incident proton is bombarded into the target surface.

Target preparation is also one of the crucial factors to consider prior to the target irradiation. Careful studies of the types of targets (i.e. electroplated targets, foil targets or mixed targets) should be carried out to minimize failures associated with the target handling before, during and after irradiation as well as optimum radioactivity yields. Enriched nickel targets $\left({ }^{64} \mathrm{Ni}\right)$ in the form of electroplated targets have been widely suggested as

\footnotetext{
*Corresponding author

E-mail address: imamkey@batan.go.id
}

the best target for ${ }^{64} \mathrm{Cu}$ production [1,2], though natural Ni target has also been of interest elsewhere [3]. Radionuclide ${ }^{64} \mathrm{Cu}$ emits $\beta^{-}(38 \%), \beta^{+}(19 \%)$ and Electron Capture (43\%) with a half-life of 12.7 hours [4]. It is the $\beta^{+}$emission which is used as the basic idea of PET in nuclear medicines. The threshold energy for ${ }^{64} \mathrm{Ni}(\mathrm{p}, \mathrm{n}){ }^{64} \mathrm{Cu}$ is nearly $2.5 \mathrm{MeV}$ and the maximum cross-section is approximately 765 mbarn which occurs at nearly $10 \mathrm{MeV}$ based on TALYS-calculated data [5].

Another important parameter relevant to the ${ }^{64} \mathrm{Cu}$ production is the target thickness as it corresponds to the radioactivity yield. Knowledge about proton distributions in the $\mathrm{Ni}$ target is, therefore, paramount to successfully determine the correct target thickness prior to proton irradiation. The proton distributions in $\mathrm{Ni}$ target can be examined from the particle's stopping power/energy loss and range, which can be calculated using Stopping and Range of Ion in Matter (SRIM) package [6]. In the SRIM codes, stopping power is defined as the energy required to slow down the incident particle during its interaction with matter over a certain distance, whereas the distance over which the ion totally stops is called the range. Mathematical equations correspond to the stopping $S(E)$ and range of ion $R(E)$ in matter have been 
described in details elsewhere [7] as can be seen in equation (1) and (2);

$$
\begin{gathered}
S(E)=-\frac{d E}{d x}=\frac{4 \pi k_{o}^{2} z^{2} e^{4} n}{m c^{2} \beta^{2}}\left[\ln \frac{2 m c^{2} \beta^{2}}{I\left(1-\beta^{2}\right)}\right. \\
\left.-\beta^{2}\right], \\
R(E)=\int_{0}^{E} \frac{1}{\left(\frac{-d E}{d x}\right)} d E,
\end{gathered}
$$

where $k_{o}=8.99 \times 109 \mathrm{~N} \cdot \mathrm{m}^{2} . \mathrm{C}^{2}, z=$ atomic number, $e=$ charge of electron (in Coulomb), $n=$ number of electron per unit volume of the target (in electrons $\left./ \mathrm{m}^{3}\right), m=$ mass of electron at rest $\left(m=9.1 \times 10^{-31} \mathrm{~kg}\right), c=$ speed of light in vacuum $\left(c=3 \times 10^{8} \mathrm{~m} / \mathrm{s}\right), \beta=$ ratio of the speed of the incident particle to the speed of light, $I=$ average excitation energy of the target (in $\mathrm{MeV}$ ), $E=$ proton energy $(\mathrm{MeV}), x=$ distance overwhich the protons travel through a target (in $\mathrm{m}$ ). Note that the SRIMcalculated data agree with experimental results within $10 \%$ accuracy or less [8].

Since the threshold energy for ${ }^{64} \mathrm{Ni}(\mathrm{p}, \mathrm{n}){ }^{64} \mathrm{Cu}$ is nearly $2.5 \mathrm{MeV}$, any proton irradiation over $2.5 \mathrm{MeV}$ will result in some radioactive yields during and at the end of the bombardment. The EndOf-Bombardment (EOB) yield $(Y)$ for any nuclear particle-produced radioisotope is not only dependent on the nuclear cross-section at a particular energy, $\sigma(E)$, but also on the stopping power, $d(E) / d x$, and some other parameters as described by [9];

$$
Y=\emptyset\left(1-e^{-\lambda t}\right) \frac{N_{A}}{M} \int_{E_{i}}^{E_{t h}}\left[\frac{\sigma(E)}{\frac{1 d(E)}{\rho d x}}\right] d E,
$$

where $\Phi$ is the number of charged particles per unit of time (in this case, it is the number of protons/second), $\lambda$ is the decay constant of the resulting radioisotope (in per second), $t$ is the duration of irradiation (in second), $N_{A}$ is the Avogadro number (in atoms $/ \mathrm{mol}$ ), $\rho$ and $M$ are the mass density (in $\mathrm{kg} / \mathrm{m}^{3}$ ) and atomic mass of the target (in atomic mass unit) respectively, $E_{i}$ is the initial energy of the incident particle (in $\mathrm{MeV}$ ), and $E_{t h}$ is the threshold energy (in MeV).

The BATAN's cyclotron is capable of generating proton beams and circularly accelerating the proton beam to a maximum energy of $26.5 \mathrm{MeV}$ in a magnetic field of $17.5 \mathrm{kGauss}$ on average and a fixed radio frequency of nearly $27 \mathrm{MHz}$. The proton source is produced in a typical Penning Ion Gauge (PIG) source by ionizing hydrogen gas using electron generated by heating up a tantalum (Ta) cathode. Details on the $26.5 \mathrm{MeV}$ proton beams can be found in reference [10].

This paper reports on the use of the SRIM codes to discuss the range and dissipated energy of energetic protons in $\mathrm{Ni}$ targets relevant to ${ }^{64} \mathrm{Cu}$ production. The results of the SRIM codes are then coupled to the cross-section obtained from the TALYS calculated data which, to the best of the author's knowledge, have not been done before. The data obtained from this simple method is expectedly useful for predicting the radioactivity yields of ${ }^{64} \mathrm{Cu}$ from enriched Ni targets, particularly for the ${ }^{64} \mathrm{Cu}$ production using the BATAN's cyclotron in the future. The EOB yields associated with the proton-irradiated $\mathrm{Ni}$ targets are also discussed for several irradiation parameters, including Ni target thickness, proton beam current and irradiation time. The predicted results are then compared to the experimental and calculated data available from a few references [11-14]. In the last section of this paper, the author also highlights that previous researchers obtained muchlower-than-expected EOB yields in their experiments because of a common mistake related to the target thickness which have not been discussed elsewhere.

\section{THEORETICAL CALCULATIONS}

\section{The SRIM-2013 calculations}

The range and deposited energy of up to $28 \mathrm{MeV}$ proton beams in a $100 \%$-enriched ${ }^{64} \mathrm{Ni}$ target were calculated using the SRIM 2013 package [6]. In the simulations, the target was bombarded by the energetic protons at normal incidence angle $\left(90^{\circ}\right.$ with respect to the target surface, hence so-called $0^{\circ}$ incidence angle) as well as at $15^{\circ}$ relative to the target normal. The $15^{\circ}$-tilted target was chosen in the simulations since it corresponds to the available target system at the BATAN's cyclotron facilities in Serpong, whereas the normal incidence angle calculations were carried out as a comparison. The proton energy deposited in the ${ }^{64} \mathrm{Ni}$ target was eventually determined from the energy dissipated in to the target by varying the target thickness between $100 \mu \mathrm{m}(0.1 \mathrm{~mm})$ and $1500 \mu \mathrm{m}(1.5 \mathrm{~mm})$.

The most important assumptions employed in the calculations include:

(1) The high vacuum pressure is kept well below 10-7 mbar and is stable during the bombardment. 
(2) The Proton source is relatively stable and no significant impurities are found in the hydrogen gas source (gas purity of $99.9999 \%$ ).

(3) Nuclear reactions between proton beams and $\mathrm{Ni}$ targets can only occur when the proton energy equals to or higher than $2.5 \mathrm{MeV}$.

(4) The target position is kept steady during the bombardment particularly after the target is moved to its tilted positions.

\section{End-Of-Bombardment (EOB) yields}

For comparison studies, the EOB yields were calculated using equation (1) in which the enriched ${ }^{64} \mathrm{Ni}$ targets of different target compositions $\left(100 \%{ }^{64} \mathrm{Ni}, 94.5 \%{ }^{64} \mathrm{Ni}, 98 \%{ }^{64} \mathrm{Ni}\right.$ and $99.858 \%{ }^{64} \mathrm{Ni}$ ) and thickness were taken into account as used in the references [11-13]. The TALYS-calculated nuclear cross-section data obtained from reference [15] were used in the yield calculations. The dependence of the EOB yields on the ${ }^{64} \mathrm{Ni}$ target thickness, proton beam current and irradiation time were also simulated in these studies. The calculated EOB yields were then compared with the experimental data [11-13] as well as with the previously predicted yields found elsewhere [13].

\section{RESULTS AND DISCUSSION}

\section{Proton deposited energy and target thickness}

The dependence of proton deposited energy on ${ }^{64} \mathrm{Ni}$ target thickness is shown in Fig. 1 which indicates that the deposited energy is directly proportional to the target thickness for proton energy between $6 \mathrm{MeV}$ and $28 \mathrm{MeV}$ and incidence angles of $0^{\circ}$ and $15^{\circ}$ with respect to the target normal. In a $0.1-\mathrm{mm}{ }^{64} \mathrm{Ni}$ target, for instance, protons dissipate nearly $7 \mathrm{MeV}$ of their total energy for both $0^{\circ}$ and $15^{\circ}$ incidence angles. The deposited energy jumps to $22.9 \mathrm{MeV}$ and $22.4 \mathrm{MeV}$ for $0^{\circ}$ and $15^{\circ}$ incidence angle respectively, when the ${ }^{64} \mathrm{Ni}$ target thickness is increased to $1 \mathrm{~mm}$. For $26.5-\mathrm{MeV}$ protons, a $1.3-\mathrm{mm}{ }^{64} \mathrm{Ni}$ target is sufficiently thick to stop the beam completely whereas a $1.5-\mathrm{mm}{ }^{64} \mathrm{Ni}$ target is required to completely dissipate a beam of 28-MeV protons.

As can be seen in Figure 1, the deposited energy for $0^{\circ}$ and $15^{\circ}$ incidence angles does not differ significantly in a relatively thin $64 \mathrm{Ni}$ target. However the percentage difference increases to a maximum value of nearly $2.2 \%$ in a $0.7-\mathrm{mm}$ thick $64 \mathrm{Ni}$ target and then it decreases steadily with increasing thickness. Note that the percentage difference is calculated by;

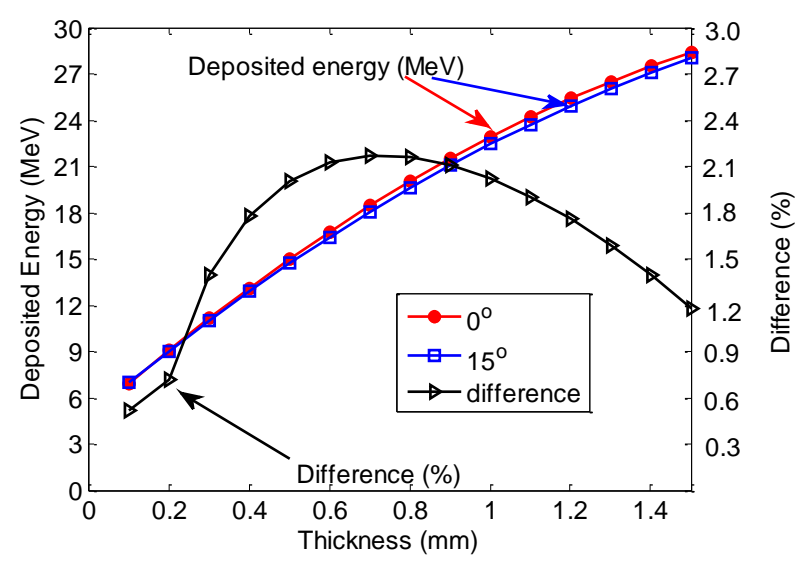

Fig. 1. SRIM-calculated proton deposited energy as a function of nickel target thickness.

$$
\text { Difference }(\%)=\frac{\left|\left(V_{1}-V_{2}\right)\right|}{\frac{1}{2}\left(V_{1}+V_{2}\right)} \times 100 \%
$$

where $V_{l}$ is the deposited energy at $0^{\circ}$ incidence angle (in $\mathrm{MeV}$ ) and $V_{2}$ is deposited energy at $15^{\circ}$ incidence angle (in $\mathrm{MeV}$ ).

\section{Dependence of EOB yields on ${ }^{64} \mathrm{Ni}$ target thickness, proton beam current and irradiation time}

Using equation (1), as stated earlier in the calculation section, the EOB yields of a 26.5-MeV proton beam at different current between $1 \mu \mathrm{A}$ and $3 \mu \mathrm{A}$ were calculated as a function of ${ }^{64} \mathrm{Ni}$ target thickness depicted in Fig. 2(a) and 2(b) which indicate similar behavior for irradiation time of 1 hour and 2 hours respectively. The rapid increase in the ${ }^{64} \mathrm{Cu}$ yields is evident when the $26.5-\mathrm{MeV}$ proton beam is irradiated into a less-than-0.5-mm $\mathrm{Ni}$ target, though the EOB yields rise further at a slower rate before they eventually level off when the target is over $1.2-\mathrm{mm}$ thick. In theory, there will be no added radioactivity yield should the $\mathrm{Ni}$ target thickness is increased further to greater than $1.5 \mathrm{~mm}$ thick.

For an hour of irradiation time, the maximum radioactivity yields are expected to be approximately $0.56 \mathrm{Ci}, 1.1 \mathrm{Ci}$ and $1.7 \mathrm{Ci}$ for proton beam current of $1 \mu \mathrm{A}, 2 \mu \mathrm{A}$ and $3 \mu \mathrm{A}$ respectively. Moreover the yields will rise by two-fold when the bombardment duration is increased to 2 hours. 




(a)

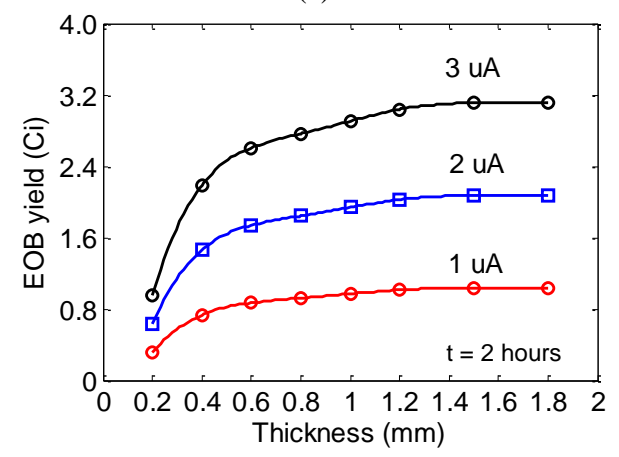

(b)

Fig. 2. EOB yields as a function of $\mathrm{Ni}$ target thickness at different proton beam current ranging from $1 \mu \mathrm{A}$ to $3 \mu \mathrm{A}$ and fixed energy of $26.5 \mathrm{MeV}$ for irradiation time of (a) 1 hour and (b) 2 hours.

In order to further study the influence of irradiation time and $\mathrm{Ni}$ target thickness over the EOB yields, a range of yield calculations were carried out with 10-minute increments, again at fixed proton energy of $26.5 \mathrm{MeV}$, and the results are shown in Fig. 3(a) for a proton beam of $10 \mu \mathrm{A}$ and also in Fig. 3(b) for a $20-\mu \mathrm{A}$ proton beam. For both simulated beam current, dramatic surge in the EOB yields can be clearly seen in the figures for all investigated $\mathrm{Ni}$ target thickness ranging from $0.2 \mathrm{~nm}$ to $1.5 \mathrm{~nm}$. EOB yields of up to $14.4 \mathrm{Ci}$ and $28.8 \mathrm{Ci}$ are expected to be produced following the irradiation of a $1.5-\mathrm{mm}$ thick $\mathrm{Ni}$ target over a period of 180 minutes ( 3 hours).

To sum up an optimum EOB yield of $560 \mathrm{mCi} / \mu \mathrm{A} . \mathrm{hr}(0.56 \mathrm{Ci} / \mu \mathrm{A} . \mathrm{hr})$ is expected to be achieved when a $1.5-\mathrm{mm}$ enriched $\mathrm{Ni}$ target is irradiated using the BATAN's $26.5-\mathrm{MeV}$ proton cyclotron. However when the target thickness is less than the optimum thickness, the EOB yield would be down to approximately $173 \mathrm{mCi} / \mu \mathrm{A} . \mathrm{hr}$ for a 200- $\mu \mathrm{m}$ Ni target.

Since the half-life of ${ }^{64} \mathrm{Cu}$ is 12.7 hours and that around $3 \mathrm{mCi}$ is required for the purpose of a patient PET diagnosis [16], a 560-mCi EOB yield would be sufficient, in theory, to diagnose over 150 patients after a 3-hours radioactivity cooling off period.

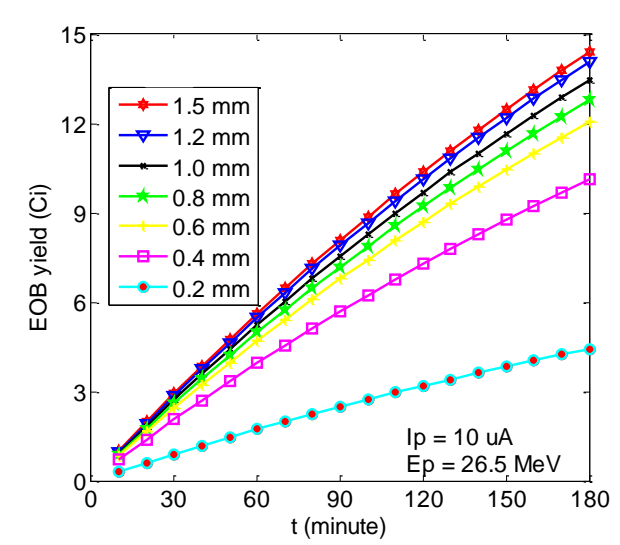

(a)

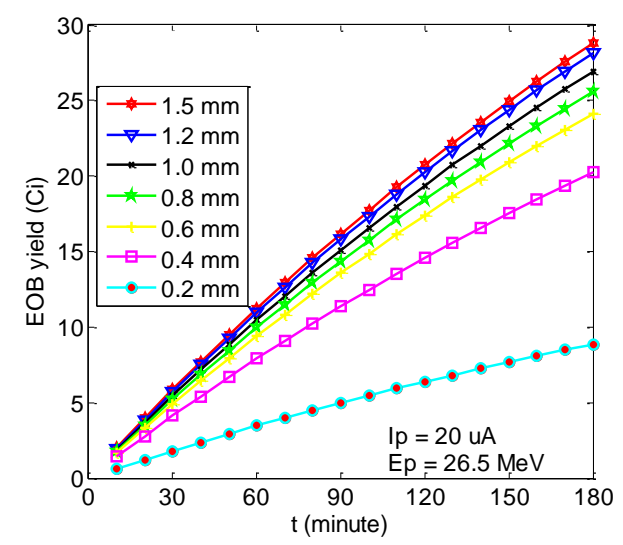

(b)

Fig. 3. EOB yields as a function of irradiation time at different $\mathrm{Ni}$ target thickness and fixed energy of $26.5 \mathrm{MeV}$ for proton beam current of (a) $10 \mu \mathrm{A}$, and (b) $20 \mu \mathrm{A}$.

\section{Comparisons with experimental data}

A range of experimental data were collected from several references to verify the calculated EOB yields as listed in Table 1 (for Ep $=12-15.5 \mathrm{MeV}$ ). Using a 12-MeV proton beam, Obata et al. [11] irradiated enriched $\mathrm{Ni}$ targets at a constant beam current of $50 \mu \mathrm{A}$. At the end of the bombardment, they obtained ${ }^{64} \mathrm{Cu}$ radioactivity yields of $3.079 \mathrm{mCi} / \mu \mathrm{A} . \mathrm{hr}, \quad 3.734 \mathrm{mCi} / \mu \mathrm{A} . \mathrm{hr}, \quad$ and $6.565 \mathrm{mCi} / \mu \mathrm{A} . \mathrm{hr}$ for target thicknesses of $127.45 \mu \mathrm{m}, 144.16 \mu \mathrm{m}$ and $277.28 \mu \mathrm{m}$ respectively. These experimental results are, however, much lower than the predicted results calculated in this report as well as those obtained elsewhere [14] as given in Table 1.

Based on the SRIM-calculated data, a $12-\mathrm{MeV}$ proton beam is able to penetrate relatively deep into a $\mathrm{Ni}$ target and pass the target at an average range of $377.2 \mu \mathrm{m}$ (Fig. 4). Therefore, the optimum yield of around $6.89 \mathrm{mCi} / \mu \mathrm{A} . \mathrm{hr}$ at this particular proton energy would only be obtained if the $\mathrm{Ni}$ target thickness was around $377.2 \mu \mathrm{m}$. However in the case of Obata, et al. investigation [11], they employed up to $277.28-\mu \mathrm{m}$ thick 
Ni targets to produce ${ }^{64} \mathrm{Cu}$, which are too thin to totally stop the incoming $12-\mathrm{MeV}$ proton beam. At a distance of $277.28 \mu \mathrm{m}$ from the Ni surface, the protons would lose nearly $10.58 \mathrm{MeV}$ of their total energy; hence, a vast number of protons would pass through the thin $\mathrm{Ni}$ target and deposit only some fraction of their total energy. This explanation also applies to the other thinner $\mathrm{Ni}$ targets. For this reason, the proton-bombarded $\mathrm{Ni}$ targets in their experiments resulted in much lower-than expected EOB yields.

Table 1. Calculated EOB yields compared to some selected experimental results [11-13] and previously predicted data [14].

\begin{tabular}{|c|c|c|c|c|c|c|c|}
\hline \multirow{2}{*}{$\begin{array}{c}\mathrm{Ep} \\
(\mathrm{MeV})\end{array}$} & \multirow{2}{*}{$\begin{array}{c}\mathrm{Ni} \\
\text { thickness } \\
(\mu \mathrm{m})\end{array}$} & \multirow{2}{*}{$\begin{array}{l}\text { Beam } \\
\text { current } \\
\text { ( } \mu \text { A.hr) }\end{array}$} & \multicolumn{3}{|c|}{ EOB yield (mCi/ $\mu \mathrm{A} . \mathrm{hr})$} & \multirow{2}{*}{$\begin{array}{l}\text { Optimum } \\
\text { thickness } \\
\qquad(\mu \mathrm{m})\end{array}$} & \multirow{2}{*}{$\begin{array}{c}\text { Deposited } \\
\text { energy } \\
(\mathrm{MeV})\end{array}$} \\
\hline & & & experimental & $\begin{array}{c}\text { Predicted } \\
\text { [13] }\end{array}$ & $\begin{array}{c}\text { This } \\
\text { calculation }\end{array}$ & & \\
\hline 12 & 127.45 & 50 & $3.079[10]$ & 6.48 & 6.89 & 377.2 & 6.68 \\
\hline 12 & 144.16 & 50 & $3.734[10]$ & 7.34 & 7.72 & 377.2 & 7.16 \\
\hline 12 & 277.28 & 50 & $6.565[10]$ & 10.8 & 10.78 & 377.2 & 10.58 \\
\hline 15.1 & 164 & 90 & $1.7[11]$ & 5.61 & 7.61 & 507.5 & 8.01 \\
\hline 15.1 & 187 & 180 & $2.79[11]$ & 6.85 & 8.29 & 507.5 & 8.53 \\
\hline 15.1 & 248 & 180 & $3.36[11]$ & 9.52 & 10.11 & 507.5 & 9.92 \\
\hline 15.5 & 311 & 120 & 5 [12] & 10.5 & 11.08 & 536.3 & 11.34 \\
\hline
\end{tabular}

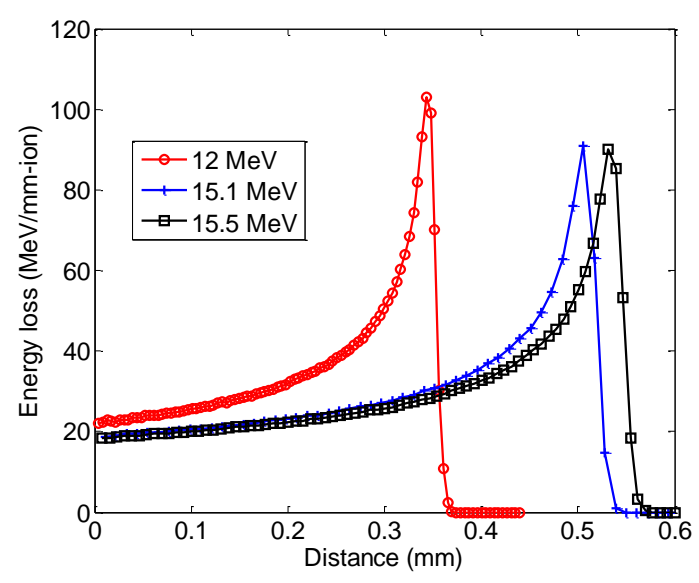

Fig. 4. SRIM-2013-simulated energy loss of 12-MeV, $15.1-\mathrm{MeV}$ and $15.5-\mathrm{MeV}$ proton beams in $\mathrm{Ni}$ target as a function of the distance traveled by the particles.

Similar ${ }^{64} \mathrm{Cu}$ production using incorrect target thickness was also done by Matarrese et al. [12] in which they irradiated several enriched $\mathrm{Ni}$ targets by a $15.1-\mathrm{MeV}$ proton beam. With higher energy than that of Obata and co-workers' experiments [11], however they prepared thinner Ni targets between $164 \mu \mathrm{m}$ and $248 \mu \mathrm{m}$. Again, based on the SRIM simulations, the average range of a $15.1-\mathrm{MeV}$ proton beam in ${ }^{64} \mathrm{Ni}$ target is approximately $507.5 \mu \mathrm{m}$ (Fig. 4). Since the Ni targets used in Matarrese et al. research were much less than the average proton range, hence they obtained only up to $3.36 \mathrm{mCi} / \mu \mathrm{A} . \mathrm{hr}$ instead of $10.11 \mathrm{mCi} / \mu \mathrm{A} . \mathrm{hr}$ yield predicted by this calculation.

Similar mistake had previously demonstrated by McCarthy and co-workers [13] where they bombarded a $311 \mu \mathrm{m}$ thick $\mathrm{Ni}$ target using a 15.5 MeV proton beam. For optimum EOB radioactivity yielded in their experimental conditions, they should have prepared around $536 \mu \mathrm{m}$ thick Ni target since this value corresponds to the average range of a $15.5 \mathrm{MeV}$ proton beam in $\mathrm{Ni}$ as can be seen in Fig. 4.

Eventhough the experimental data discussed here are for proton energy below $26.5 \mathrm{MeV}$, it is expected that for $26.5 \mathrm{MeV}$ protons the calculated results will be close to the experimental data. Overall these calculations agree with the previous predicted data found in reference [14] with a maximum difference of less than $10 \%$. The discrepancies are largely due to different cross-section data employed in the calculations.

\section{CONCLUSION}

Enriched Ni target thickness, proton beam current and irradiation time are among the very important parameters to consider for the purpose of successful ${ }^{64} \mathrm{Cu}$ production using the BATAN's cyclotron. For a $26.5 \mathrm{MeV}$ proton beam, the optimum target thickness is nearly $1.5 \mathrm{~mm}$ which yields up to $560 \mathrm{mCi} / \mu \mathrm{A} . \mathrm{hr}$ at the end of the bombardment. Comparisons with some selected experimental data indicate that the much-lowerthan-expected EOB yields are mainly due to incorrect target thickness prepared for the irradiation. Nevertheless these calculations are in good agreement with the previous predicted data with a maximum difference of less than $10 \%$. In addition, the results of this study indicate that the SRIM codes can be employed to assist in calculating the radioactivity yields of ${ }^{64} \mathrm{Cu}$ when enriched Ni targets are bombarded using $26.5 \mathrm{MeV}$ proton beams as well as other proton energies and material targets. Moreover, the calculated data can be used as a theoretical reference once experimental production of ${ }^{64} \mathrm{Cu}$ is conducted in the near future using the BATAN's cyclotron in Serpong.

\section{ACKNOWLEDGMENT}

The authors gratefully acknowledge the Indonesian National Nuclear Energy Agency (BATAN) for financially supporting this research program. Meaningful discussion with 
Mr. Hari Suryanto and Rajiman is also greatly appreciated.

\section{REFERENCES}

1. Van So Le, J. Howse, M. Zaw, et al., Appl. Radiat. Isot. 67 (2009) 1324.

2. M.A. Avila-Rodrigueza, J.A. Nyeb and R.J. Nickles, Appl. Radiat. Isot. 65 (2007) 1115.

3. A.H. Al Rayyes and Y. Ailouti, WJNST 3 (2013) 72.

4. C.M. Lederer and V.S. Shierley, Table of Isotopes, 7th ed. MacMillan, New York (1978) 5 .

5. A.J. Koning, D. Rochman, S.V.D. Marck, et al., TENDL-2013: TALYS-Based Evaluated Nuclear Data Library, www.talys.eu/tendl2013.html. Retrieved in 10 June (2014).

6. J.F. Ziegler, M.D. Ziegler and J.P. Biersack, The Stopping and Range of Ions in Matter (SRIM) (2010), Nucl. Instrum. Methods. Phys. Res., Sect. B 268 (2010) 1818.

7. J.F. Ziegler, J.P. Biersack and M.D. Ziegler. Stopping and Range of Ions in Matter, in: SRIM Co., Chester, MD. (2008) 1.

8. H. Paul, Nucl. Instrum. Methods. Phys. Res., Sect. B 273 (2012) 15.
9. C. Gonzalez Lepera (2012), PET Radionuclides Production Cyclotron Selection and Location, Cyclotope and Experimental Diagnostic Imaging, The University of Texas MD Anderson Cancer Center Houston, TX. www.aapm.org/meetings/08SS. Retrieved in 31 March 2014.

10. Sunarhadiyoso, Fundamentals of Cyclotron Technology, in: Training on Cyclotron Technology and Application for Technicians, Center for Radioisotope and Radiopharmaceuticals, BATAN, Indonesia (1993) 1. (in Indonesian)

11. A. Obata, S. Kasamatsu, D.W. McCarthy, et al., Nucl. Med. Biol. 30 (2003) 535.

12. M. Matarrese, P. Bedeschi, R. Scardaoni, et al., Appl. Radiat. Isot. 68 (2010) 5.

13. D.W. McCarthy, R.E. Shefer, R.E. Klinkowstein, et al., Nucl. Med. Biol. 24 (1997) 35.

14. F. Szelecsenyi, G. Blessing and S.M. Qaim, Appl. Radiat. Isot. 44 (1993) 575.

15. A.J. Koning, D. Rochman, S.V.D. Marck, et al., TENDL-2013: TALYS-based evaluated nuclear data library, www.talys.eu/tendl2013.html. Retrieved in 10 March (2014).

16. C.J. Anderson, F. Dehdashti and P.D. Cutler, J. Nucl. Med. 42 (2001) 213. 